\title{
Lexical Variation in the Economic Sociolect of the Italian and Spanish Newspapers
}

\author{
Angelo Cece \\ Department of Spanish Philology, General Linguistics and Theory of Literature, University of Alicante, Alicante, Spain \\ Email address: \\ angelocece@libero.it \\ To cite this article: \\ Angelo Cece. Lexical Variation in the Economic Sociolect of the Italian and Spanish Newspapers. International Journal of Language and \\ Linguistics. Vol. 9, No. 3, 2021, pp. 74-79. doi: 10.11648/j.ijl1.20210903.12
}

Received: April 13, 2021; Accepted: April 27, 2021; Published: May 14, 2021

\begin{abstract}
Frequent contacts between the English language and Italian and Spanish languages speeds up the anglicisms lexical transfer process in these neo-Latin languages. Contact situations open up a series of communication channels between different social groups which are reflected in the use of English terms adopted by the Italian and Spanish. The Italian and Spanish newspapers economic context is conditioned by the presence of a large number of lexical anglicisms, as an attestation of linguistic primacy and meaning of cultural prestige. The scale of this phenomenon is quantified by observing real facts, in accordance with the quantitative model of variationist sociolinguistics. Over the last half-century, it has seen a growth in the study of the phenomenon of bilingualism, especially between the Romance languages and English language. The phonological variation studies have been added the lexical and semantic. However, the approaches to these phenomena are not always analysed from a sociolinguistic point of view. The vast literature tends to describe intuitively situations of changes and lexical substitutions from English on the economic Italian and Spanish press, rather than a quantitative evaluation of the phenomenon. This article shows thus the real impact of anglicisms (code-switching and calque) on the economic and financial Italian and Spanish newspapers. In addition, the collected data analysis made it possible to compare the two social contexts, from which the different circumstances of lexical importations and substitutions are determined.
\end{abstract}

Keywords: Anglicisms, Lexical Transfer Process, Economic Press, Statistical Inference

\section{Introduction}

Research carried out in the sociolinguistic field for more than half a century has shown language varies, based on the correlation of linguistic factors (dependent variable) with social behaviours (independent variable). The linguistic structure is frequently conditioned by "internal" and "external" factors, so it is deduced that the relationship between these two variables is not random [17, 43, 49]. In this sense, the quantitative approach of sociolinguistics shows that the linguistic variation of a community depends on social and situational change $[10,15,26]$. A language also changes as a function of the individuals belonging to a particular social group $[3,11]$. In other words, the different subjects of a community differ in gender, age, geographical origin and socio-cultural level [24, 31]. Therefore, a language changes in relation to the members of a society, in terms of written and oral register [13, 25, 32, 48]. On the phonological, morphological, lexical and syntactic levels, the constituent elements of a language (variables) are changeable and sometimes assume different forms (variants) [20]. The language of a social group inevitably shows variants with respect to the standard variety, since the different social categories use the language differently.

At moment when two (or more) different language communities come into contact, are created social situations which condition the use of languages, so that, some elements of one language move from one language system to another [9]. At the lexical level, are the words which are transferred from one language to another, in the forms of loan $[45,46]$, code- switching [44] and calque [21]. In this analysis, the linguistic and social integration of the lexical units of "loans" have no relevance, since it is considered as a linguistic process concluded with respect to an ongoing evolution. On the contrary, the lexical import of the "code- switching" and the lexical substitution of "lexical calque", as they give an immediate vision of the linguistic and cultural orientation of a community. Therefore, it was decided to analyse these two 
linguistic variables within the social contexts of Italian and Spanish economic newspapers.

\section{Objectives and Methodology of the Research}

Each language has changed its characteristics in different periods of history $[1,30]$. This variability has always been more highlighted in the register by the surprising progress, diffusion and use of the new means of communication which, unlike the traditional ones, had increased the flow of communication between languages. Contact between the Romance languages and English led to the lexical transfer process. The social situations of language contact have undoubtedly facilitated the communication of different groups within the speaking communities. The prolonged interactions between their members, based on the sharing of values and beliefs, have facilitated the process of linguistic and cultural convergence, in a balanced relationship between the social dimension and linguistic and cultural expression [44]. The phenomena of language contact have frequently originated situations of language transfer, which have manifested themselves in the language variables of codeswitching and lexical calques. The social contexts analysed showed a considerable number of anglicisms coming from sectorial languages and also used in non-specialized communication situations [2, 18, 22]. It is about terms and phrases which are characterized by the import and substitution of the lexical elements, because they are not adapted to the language system of the receiving language and are not adopted by the host community [44].

\subsection{The Corpus and Sociolinguistic Methodology}

From an empirical and complementary perspective, I present a study that I have conducted on the impact of lexical anglicism on the economic sociolect of Italian and Spanish periodicals [5]. The study is realized form of a description of the language transfer process and quantification of the distribution of lexical anglicisms (code-switching and calque) in a representative and significant sample of 60 newspapers and economics national inserts of greater circulation and distribution $^{1}$. More specifically, the copies analysed are 30 Italians and 30 Spanish, of which five for each newspaper and economic insert published in Italy and Spain between 2012 and 2015.

The methodology adopted is attributable to the quantitative model of variationist sociolinguistics, which also implies qualitative analysis [26]. The "inductive method" for the collection and analysis of data is adopted, and the "deductive method" for the explanation and interpretation of the social phenomenon of language transfer. The dependent language variables taken into account are: a) categorical codeswitching; b) variable code-switching; c) categorical lexical

1. Data, Accertamenti Diffusione Stampa (ADS) and Oficina de la Justificación de la Difusión (OJD) calque; d) variable lexical calque. The independent social variables examined are: a) the Italian economic newspapers of greater circulation; b) the Italian economic inserts of greater circulation; c) the Spanish economic newspapers of greater circulation; d) the Spanish economic inserts of greater circulation. Finally, it is classified as variable or variant of the underlying variable every lexical element of the corpus emerged on the surface.

\subsection{The Hypotheses of the Advanced Search}

1) The total of the occurrences of code-switching in the economic newspapers and in the economic inserts of the Italy national general newspapers information is greater than the total of the occurrences of the lexical calque;

2) The total of the occurrences of code-switching in the economic newspapers and in the economic inserts of the Spanish national general newspapers information is greater than the total of the occurrences of the lexical calque;

3) The total of the occurrences of code-switching in the Italian economy national newspapers is quantitatively higher than the Spanish equivalents;

4) The total of the occurrences of calque in the Italian economy national newspapers is quantitatively higher than the Spanish equivalents;

5) The relationship between code-switching and Italian economic newspapers is statistically significant;

6) The relationship between code-switching and Spanish economic newspapers is statistically significant;

The corpora analysed were:

a) Italian economic newspapers: Il Sole 24 Ore, MFMilano Finanza e Italia Oggi;

b) Economic inserts of the Italian generalist newspapers: Corriere Economia of the Corriere della Sera, Affari \& Finanza of the La Repubblica and Tuttosoldi of the La Stampa;

c) Spanish economic newspapers: Expansión, Cinco Días e El Economista;

d) Economic inserts of the Italian generalist newspapers: Negocios of the El País, Mercados of the El Mundo and Dinero of the La Vanguardia.

Finally, the copies were selected without any prior calculation, regardless of any influential circumstances or relevant facts, political orientations or ideological positions, sales day or number of pages appeared [32]. The only determination was to evaluate at least one print for each kind of newspaper of all its three years' publications.

\section{Statistical and Computer Analysis of Lexical Anglicisms}

In last few decades, sociolinguistic studies have produced significant results in both phonological and lexical fields. Quantitative analyses showed that linguistic variation is not random but follows certain rules, which are not categorical but conditioned by social situations. The occurrences are 
manifested statistically in different forms compared to a preestablished form, since external factors give rise to alternative forms that follow the rules of the linguistic community [33]. Linguistic, social and cultural factors are directly linked to the process of linguistic change. Thus, the social characteristics and the shared knowledge of the language system of a community need to be defined punctually, through direct observation of facts. Temporal, geographical and social differentiation is a necessary condition for a careful analysis of linguistic behaviour, since the existence of social variables is real and determines linguistic variations within a communicative framework that is real $[6,12]$. The consideration of the internal change of the linguistic system alone does not therefore guarantee an integral analysis of the process of linguistic variation. In that, it is free of situational heterogeneity and generational diversity of social groups living in a linguistic community [27-29].

\subsection{Absolute and Relative Frequency of the Different Types of Lexical Anglicisms}

Economy newspapers have a large number of lexical anglicisms, particularly in the Italian press, whose frequencies are about three times higher than in Spain. In this sense, the results of the quantitative analyses reveal that the difference in the different lexical types of code-switching between the two geographical, social and economic contexts is significant. However, it should be noted that in Spanish newspapers the frequency of lexical calque is relatively higher than in Italian newspapers. Their minimum value has no importance in this study, which, instead, is characterized by the almost absolute predominance of the different types of lexicalizations of code-switching in both social contexts. This symptomatic figure shows how much the Italian and Spanish societies share Anglo-Saxon social and cultural models [4, 8, 36]. In this sense, the press is a valuable tool of cultural propagation, through the differentiated use of terms and phrases imported from English.

In the case of categorical code-switching, the integral lexical element dominates over the adaptation, while in the case of variable code-switching, the lexical element appears to be less of a preponderance than the adaptation (see the following table).

Table 1. Absolute and relative frequency of the different lexical types of code-switching and lexical calque, depending on the Italian and Spanish economic press.

\begin{tabular}{lllll}
\hline LEXICAL ANGLICISMS & n. & $\mathbf{\%}$ & Total & \% \\
\hline Categorical code-switching & 2.462 & 63,14 & \multirow{2}{*}{3.810} & 97,72 \\
Variable code-switching & 1.348 & 34,58 & & \\
Categorical lexical calque & 81 & 2,08 & & \multirow{2}{*}{89,28} \\
Variable lexical calque & 8 & 0,2 & & 100 \\
TOTAL & & & 3.899 & 100 \\
\hline
\end{tabular}

In terms of percentages compared to total occurrences, the results of the sample analyses show a clear supremacy of the different lexical types of code-switching (97.72\%) over lexical calque $(2.28 \%)$. Category code switching are the linguistic variables with the highest value $(63.14 \%)$, followed by the percentage of variable cod-switching $(34.58 \%)$. The percentage gap between categorical code-switching and variable code-switching is visibly large. The categorical code-switching are almost twice of the variables, so that it is deduced that economic journalism mainly gives importance to English voices and expressions with respect to the possibilities of use of the corresponding lexical variants.

The calculation of the frequencies of the categorical codeswitching and the variable code-switching clearly establishes their superiority against the categorical lexical calque $(2.28 \%)$ and the variable lexical calque $(0.2 \%)$. This shows the little relevance of lexical calque in the Italian and Spanish economic communication.

In any case, the predominance of code-switching in the economic newspapers and inserts of the corpus confirms the first and second hypothesis of the research. These two hypotheses are consolidated with the calculation of the frequencies and relative percentages of the sets of dependent variants, subdivided in relation to the variable standard of belongings that have manifested in the two social contexts (see the following table).

Table 2. Absolute and relative frequency of sets of different lexical types of code switches and lexical casts, depending on the Italian and Spanish economic press.

\begin{tabular}{lllll}
\hline LEXICAL ANGLICISMS & n. & \% & Total & \% \\
\hline Categorical code-switching & 819 & 82,15 & 975 & 97,8 \\
Variable code-switching & 156 & 15,65 & & \\
Categorical lexical calque & 16 & 1,6 & 22 & 2,2 \\
Variable lexical calque & 6 & 0,6 & & 100 \\
TOTAL & & & 997 & 100 \\
\hline
\end{tabular}

It is reaffirmed a clear predominance of the different lexical types of code-switching $(97.8 \%)$ over lexical calque $(2.2 \%)$. The supremacy relation of categorical codeswitching (82.15\%) against variable code-switching (15.65\%) confirms the trend described above, which concludes with a still small presence of categorical lexical calque $(1.6 \%)$ and variable lexical casts $(0.6 \%)$.

These results indicate a linguistic and social behaviour characterized by the almost total import of lexical anglicisms that is preferred to linguistic substitution, and by the sharing of Anglo-Saxon models that are imitated by the middle and high Italian and Spanish social classes, interested in this study.

Nevertheless, the Italian economic press and the Spanish economic press differ in the quantity and frequency distribution of the different lexical types of categorical codeswitching and variable code-switching. The Italian economic newspapers show a $75.51 \%$ frequency of code-switching as against $22.21 \%$ in the economic Spanish newspapers. Furthermore, within the two socio-economic contexts there is a different trend: discontinuous in the Italian one $(26.29 \%$ vs. $49.22 \%$ ), more regular in the Spanish one $(10.39 \%$ vs. $11.82 \%)$.

As regards the third hypothesis of research, as it has 
already been pointed out, the different lexical types of codeswitching in the Italian economic newspapers and inserts are of greater number of English to the correspondent in the equivalent Spanish press. The Analysis of economic samples shows the gap between the Italian economic press (76.61\%) and the Spanish press (23.39).

Instead, the fourth hypothesis of this research is not confirmed, as it is not the Italian economic newspapers and inserts which have the greatest number of lexical calque but the Spanish ones. The percentages of the different lexical types of categorical and variable calque related to the Italian economic press are slightly lower $(1.1 \%)$ than the percentages of the same lexical typologies of the Spanish economic press $(1.18 \%)$. The social and cultural factors of Italian economic inserts determine the lower frequency of lexical calque, as well as the increase in code-switching. In particular, the Italian insert Affari \& Finanza presents a percentage of $25.31 \%$ of the categorical code-switching and $12.23 \%$ of the variable codeswitching, without any lexical calque.

A relevant figure that emerges is related to the increased frequency of use of some terms that is observed in both social contexts. As for the Italian economic press, the codeswitching (categorical and variable) with the highest frequencies in the corpus are made in (referred almost exclusively to Italian products) business, export, brand marketing, online and smartphone. They are terms related to brand, business and computing. The Italian economy finds in the export of Italian products a valid support: the Italian product still possesses a value of social prestige, despite the processes of globalization of the markets have changed the forms of international trade [7]. In this respect, electronic devices and computer applications are the main factors for disseminating information, facilitating interconnections and increasing the data flows and socio-economic relationships of the network [47].

In a somewhat way, the economic Spanish press presents English expressions and voices related to financial and marketing activities, as well as computer tools (hardware and software) of various kinds, often linked to the network. The major occurrences of the different lexical types of codeswitching (categorical and variable) recorded in the economic Spanish newspapers are boom, software, bad bank, online, smartphone and marketing. Except for the reference of Italian newspapers to Italian brands and the trade dynamics related to them, the variables and lexical variants most present in the Italian and Spanish economic newspapers and inserts belong to the same semantic field, consisting of words related to the economic crisis and technological innovation $[14,16,34,35,38-42,50,51]$.

\subsection{Chi-Square Test of Independence Between the Two Significant Linguistic Variables}

In the last analysis, in order to give a more precise interpretation of the data obtained, the statistical inference method is applied. The objective is to verify whether the different lexical types of the occurrence of code-switching (categorical and variable) depend on the respective sociocontexts, and whether there is a statistically significant relationship between the linguistic variable and the extra linguistic variable (see the following table).

Table 3. Text of the $X^{2}$ distribution of the total number of code-switching (categorical and variable), depending on the Italian and Spanish economic press.

\begin{tabular}{lll}
\hline OBSERVED FREQUENCY & Italian economic press & Spanish economic press \\
\hline Categorical code-switching & 2.002 & 460 \\
Variable code-switching & 942 & 406 \\
Total & 2.944 & 866 \\
\hline & & 2.462 \\
\hline EXPECTED FREQUENCY & Italian economic press & Spanish economic press \\
\hline Categorical code-switching & 1.348 \\
Variable code-switching & $1.049,13$ & 567,87 \\
Total & 2.944 & 298,13 \\
\hline
\end{tabular}

The relationship of independence between the codeswitching and the economy Italian press, and the economic Spanish press is verified by the chi-square test $\left(\mathrm{X}^{2}\right)$.

The relationship of independence between the code switches and the Italian, and Spanish economic press is verified by the chi-square text $\left(\mathrm{X}^{2}\right)$.

The text consists in contrasting the hypothesis of independence HO (null hypothesis) between the codeswitching (categorical and variable) and the Italian and Spanish social contexts, and to present an alternative hypothesis H1 (hypothesis of the research), by showing linguistic variables depend on their respective social contexts The significance level is $5 \%$, which is the threshold established for the reliability of $X^{2}$. Any value above this percentage determine the non-acceptance of the independence hypothesis in favour of the study one.

$$
X^{2}=\sum \frac{(f+f) 2}{f}=77.89
$$

Degree of liberty, D. F.=1

P-value: $<0,001$

The distribution text of $\mathrm{X}^{2}$ reveals the linguistic variables are dependent on the two countries, Italy and Spain. The text value of $X^{2}$ of $77.89(<0.001)$ is much higher than the above number. Therefore, it is possible to reject the hypothesis of independence and accept that of the research. Thus, the codeswitching (categorical and variable) are distinctly in function of the Italian and Spanish social variables.

Furthermore, these data prove that there is a significant relationship between the linguistic and social variables $(p<$ 
0.001), for which the last two hypotheses of this investigation are confirmed.

As far as the contingency tables, we observe there is a different orderly and systematic linguistic change between the two social realities. The data indicate a difference in the use of code-switching (categorical and variable) in the Italian social context compared to the Spanish equivalent one. In Italian economic newspapers, the frequency of categorical code-switching observed $(2,002)$ is higher than the expected frequency $(1,894.13)$. Similarly, in the Spanish economic newspapers the observed frequency of variable code-switching (406) is higher than the expected frequency (298.13). The Italian economic press is influenced by English more than it could be expected, since it opts for the import of the categorical form of lexical anglicism compared to a more differentiated use of the variants. Opposite occurs in the Spanish economic press, which proportionately adapts several lexical variants to the same linguistic variable.

\section{Conclusions}

In this study the results presented were processed, evaluated and interpreted in accordance with the objectives of the research. The qualitative and quantitative analyses of the different lexical types have shown a significant impact of anglicism (albeit in different degrees) on Italian and Spanish economic newspapers and inserts [14, 16, 19, 23, 33, 37, 42]. This phenomenon has been quantified without renouncing the quality of the data extrapolated from the analysis of the chosen samples.

The empirical and scientific perspective adopted has allowed to determine the real dimension of the impact of the different lexical types of code-switching and lexical calque in the Italian and Spanish economic press. This was made possible by the sociolinguistic differentiation between the initial phase of linguistic contact and the final act of the lexical transfer process. In other words, the phenomena of import and substitution of lexical anglicism was separated from the social (as well as linguistic) acceptance of the integrated loan.

Many of the studies in this field interpret the process of lexical transfer differently - or even ignore it, for which different classifications are proposed. Therefore, it is necessary to define the concept of lexical anglicism unambiguously and to adopt a common terminology as a starting point, in order to give a single interpretation to the complex phenomenon of variation and linguistic change.

\section{References}

[1] Ammon, U. et al. (ed.): 1987-1988, Sociolinguistics. An international handbook of the science of language and society, 2 voll., Berlin, Walter de Gruyter.

[2] Beccaria, G. L.: 2006, For defense and for love. The Italian language today. Milan, Garzanti.
[3] Berruto, G.: 1980, The social variability of language. Turin, Loescher.

[4] British Council: 2018, The Future Demand for English in Europe: 2025 and Beyond. (Online), https://www.britishcouncil.org/sites/default/files/future_dema nd_for_english_in_europe_2025_and_beyond_british_council 2018.pdf.

[5] Cece, A.: 2016, The impact of economic globalization and lexical anglicism on the economic sociolect of the Italian and Spanish newspapers and inserts, dissertation (unpublished), Alicante, University of Alicante.

[6] Crystal, D.: 2011, "The consequences of global English", in Cervantes Institute \& British Council (ed.), 59-65.

[7] De Mauro, T.: 2002, Italian 2000. The audience and the motivations of Italian widespread among foreigners. Rome, Bulzoni.

[8] EU - Publications Office of the EU, Decision No 508/2000/EC of the European Parliament and of the Council of 14 February 2000 establishing the Culture 2000 programme.

[9] Extra, G., \& Verhoeven, L. (eds.): 1993, Immigrant languages in Europe. Clevedon, Multilingual Matters.

[10] Fishman, J. A.: 1966, 'Language maintenance and language shift as a field of inquiry', in J. A. Fishman, V. C. Nahirny, J. E. Hofman \& R. G. Hayden (eds.), Language Loyalty in the United States, Mouton, The Hague, 424-458.

[11] Fishman, J. A.: 1971, "The sociology of language: An interdisciplinary social science approach to language in society", in J. A. Fishman (ed.), Advances in the Sociology of Language Vol. I, Mouton, The Hague, 217-104.

[12] Fishman, J. A., Cooper, R. L. \& Rosenbaum, Y.: 1977, 'English around the world', in J. A. Fishman, R. L. Cooper \& A. W. Conrad (eds.), The Spread of English, Massachusetts, Newbury House, Rowley, 77-107.

[13] Gimeno, F.: 1990, Sociolinguistics and Spanish dialectology, $2^{\mathrm{a}}$ ed., Alicante, Universidad de Alicante, 1993.

[14] Gimeno, F.: 2008, "The response of Spanish language to economic globalization and lexical anglicism”, Proceedings of the VI International Congress of "The Spanish of America", Valladolid, Provincial Council of Valladolid, 251-68.

[15] Gimeno, F. \& Gimeno, M. V.: 2003, The linguistic shift from Spanish to English, Madrid, Cátedra.

[16] Giovanardi, C. e Trifone, P.: 2012, Italian in the world. Rome, Carocci.

[17] Goebl, H. et al. (ed.): 1997, Contact Linguistics. An International Handbook of Contemporary Research, 2 voll., Berlin, Walter de Gruyter.

[18] Gotti, M.: 1991, Specialized languages: linguistic characteristics and pragmatic criteria, Florence, La Nuova Italia.

[19] Graddol, D.: 1997, The future of English?, London, The British Council.

[20] Haensch, G.: 1982, "Typology of lexicographical works", in G. Haensch et al., 1982, 95-187. 
[21] Haensch, G. et al.: 1982, Lexicography. From theoretical linguistics to practical lexicography, Madrid, Gredos.

[22] Hoffmann, L.: 1998, Specialty languages. Selection of texts, Barcelona, IULA-UPF.

[23] Instituto Cervantes y British Council (eds.): 2011, Word by word, Madrid, Santillana.

[24] Labov, W.: 1966, The social stratification of English in New York, Washington, D. C., Center for Applied Linguistics, 2006.

[25] Labov, W.: 1972, Sociolinguistic models, Madrid, Cátedra.

[26] Labov, W.: 1982, "Building on empirical foundations", in W. P. Lehmann \& Y. Malkiel (ed.), 1982, 17-92.

[27] Labov, W.: 1994, Principles of linguistic change. Vol. 1: internal factors, 2 voll., Madrid, Gredos, 1996.

[28] Labov, W.: 2001, Principles of linguistic change. Vol. 2: social factors, 2 voll., Madrid, Gredos, 2006.

[29] Labov, W.: 2010, Principles of linguistic change. Vol. 3: Cognitive and cultural factors, Oxford, Wiley-Blackwell.

[30] Lehmann, W. P. y Malkiel, Y. (eds.): 1982, Directions for historical linguistics: A symposium, Austin, University of Texas Press.

[31] López Morales, H.: 1983, Social stratification of Spanish in Porto Rico, Mexico, UNAM.

[32] López Morales, H.: 1989, Sociolinguistics, Madrid, Gredos, $3^{\text {rd }}$ ed., 2004.

[33] López Morales, H.: 2006, The globalization of the Hispanic lexicon, Madrid, Espasa Calpe.

[34] López Morales, H.: 2010, The journey of Spanish around the world, Madrid, Taurus.

[35] López Morales, H.: 2012, The Spanish language in today's world, Valencia, Aduana Vieja.

[36] Lorenzo, E.: 1987, "Anglicisms in the press", in Proceedings of the First Meeting of Academies of the Spanish Language on Language and Media, Association of Academies of the Spanish Language (ed.), Madrid, Royal Spanish Academy, 71-79.

[37] Mackey, W. F.: 2003, "Forecasting the fate of languages", in J. Maurais \& M. A. Morris (eds.), 2003, 64-81.
[38] Marcos-Marín, F. A.: 2006, The challenges of Spanish, Madrid, Vervuert / Iberoamericana.

[39] Maurais, J.: 2003, “Towards a new linguistic world order?", in J. Maurais \& M. A. Morris (eds.), 2003, 13-36.

[40] Maurais, J. \& Morris, M. A.: 2003, "Introduction", in J. Maurais \& M. A. Morris (eds.), 2003, 1-10.

[41] Labov, W. (eds.): 2003, Languages in a globalising world, Cambridge, Cambridge University Press.

[42] Moreno, F. \& Otero, J.: 2007, Atlas of the Spanish language in the world, 2nd ed. Madrid, Real Institute. Elcano Institute, Cervantes Fundación Telefónica.

[43] Poplack, S.: 1988, "Linguistic Consequences of Language in Contact: A Variationist Analysis Model ", Langage et Société, $43,23-48$

[44] Poplack, S. \& Sankoff, D.: 1988, "Code-switching", in U. Ammon et al. (eds.), 1987-1988, II, 1174-80.

[45] Rodríguez González, F. e Lillo Buades, A.: 1997, New dictionary of anglicisms, Madrid, Gredos.

[46] Sánchez-Martín, F. J.: 2011, “The work of the Royal Spanish Academy in the advancement of the 23rd edition of the Dictionary of the Spanish language: the English voices". Lexis, XXXV (1), 143-61.

[47] Sasot Mateus, A.: 2004, "The process of globalization", in Universal History, V. 20. End of the century. The keys to the 21 st century. Editorial Salvat, 165-216.

[48] Silva-Corvalán, C.: 1988, Sociolinguistics: theory and analysis. Madrid, Alhambra.

[49] Silva-Corvalán, C.: 1994, Language contact and change. Spanish in Los Angeles, New York, Clarendon Press/Oxford University Press.

[50] Silva-Corvalán, C.: 2001, Sociolinguistics and pragmatics of Spanish, Washington, D. C., Georgetown University Press.

[51] Vedovelli, M.: 2010, "Problems of Italian language policy in the world: the university system, the business system", Conference proceedings, Brussels, IIC, pp. 36-43. 